\title{
APRESENTAÇÃO \\ POR UMA CIÊNCIA ECONÔMICA FEMINISTA
}

\author{
Fabiana Sanches Grecco \\ (Doutoranda em Ciência Política - Unicamp) \\ Juliane da Costa Furno \\ (Doutoranda em Desenvolvimento Econômico - Unicamp) \\ Marilane Oliveira Teixeira \\ (Doutora em Desenvolvimento Econômico - Unicamp)
}

A Economia Feminista é um campo de estudos da Ciência Econômica e uma abordagem política que orienta diversos grupos feministas. A sua construção é fruto da imbricação entre a produção acadêmica e as lutas feministas e é desenvolvida tanto nos centros de estudos e pesquisas como nos espaços de atuação política feminista: Organiz̧ações Não Governamentais (ONGs), movimentos sociais e associações de mulheres trabalhadoras.

A consolidação acadêmica desse campo pode ser verificada a partir da década de 1990, com a formação da International Association For Feminist Economics (IAFFE) e do periódico Feminist Economics, além de uma série de livros, como "Beyond Economic man: feminist theory and economics", organizado por Marianne Ferber e Julie Nelson (University of Chicago Press, 1993); "Mujeres y Economía. Nuevas perspectivas para viejos y nuevos problemas", organizado por Cristina Carrasco (Icaria editorial, 1999); e outros mais recentes, como "Con voz, propia: la economía feminista como apuesta teórica y politica”, também organizado por Carrasco (La Oveja Roja, 2014). Apesar dessa consolidação acadêmica ser relativamente recente, os trabalhos das 
economistas feministas se iniciaram em meados dos anos 1970, como as pesquisas de Barbara Bergmann (1973), e contribuições à Ciência Econômica com perspectivas que podem ser consideradas feministas são encontradas desde o século XIX, como os trabalhos de Barbara Bodichon e Ada Heather-Bigg, como demonstra Michèle Pujol (1992).

$\mathrm{Na}$ Economia Feminista, no entanto, se aglutinam propostas e enfoques diversos. Muitas autoras estabelecem diálogos, por exemplo, com a economia marxista, com a economia ecologista ou com feminismos antirracistas, pós-coloniais, decoloniais e pós-modernos. Algumas correntes estão mais inclinadas à prática política do que à elaboração teórica. A Economia Feminista é, portanto, tão plural quanto as perspectivas feministas podem ser. Algumas autoras, como Amaia Pérez Orozco (2005), inclusive pensam tal pluralidade por meio da separação entre "economias feministas conciliatórias”, que não rompem com lógicas mercantis de produção de conhecimento, e "economias feministas rupturistas", em que - ao analisar a experiência das mulheres - não ocultam "as mulheres cujas vozes têm menor espaço em um contexto de hegemonia ocidental na produção do conhecimento" (Pérez Orozco, 2005, p. 53). Nessas definições sobre o que a Economia Feminista abarca, as "economias de gênero" seriam aquelas que apenas incorporariam os estudos de gênero aos paradigmas econômicos existentes, bastante diferente da construção de novos métodos e rupturas de paradigmas que as economistas feministas propõem fazer (Pérez Orozco, 2005 e Antonella Picchio, 2012).

De um modo geral, as análises produzidas pelas economistas feministas travam uma crítica contundente contra as teorias econômicas predominantes do mainstream, denominadas de ortodoxas. Nessa crítica, sua colaboração mais importante é justamente a afirmação do ponto de vista feminista (feminist standpoint) na ciência (Harding, 1987). A importância da teoria feminista, no geral, e da Economia Feminista, em particular, está assim, exatamente em seu ponto de vista político, o que torna a ciência mais objetiva e menos negligente (Ferber e Nelson, 1993; Harding, 1987, 1992 e 1995). É com a busca de mais objetividade na Ciência Econômica que a Economia Feminista denuncia a falsa neutralidade científica que está ancorada em um olhar androcêntrico (Carrasco, 2006; England, 1993). 
Considerando essas distinções, no espaço acadêmico brasileiro a economia feminista ainda é pouco difundida, sobretudo a sua vertente rupturista. Contudo, no que se refere à organização política, a abrangência da Economia Feminista no país é significativa. A partir do final da década de 1990, diversos grupos feministas que se preocupam com o enfrentamento às investidas neoliberais e com a valorização das práticas econômicas que se diferenciam e se distanciam das práticas tipicamente capitalistas, abriram espaço para esses debates por meio da Economia Feminista. Nesse cenário destacam-se as ONGs Sempreviva Organização Feminista (SOF), em São Paulo/SP; a Casa da Mulher do Nordeste (CMN), em Recife/PE; e a Guayí - Democracia, Participação e Solidariedade, em Porto Alegre/RS. Destacam-se nesse cenário, também, a Rede de Economia Solidária e Feminista (RESF Nacional), a Rede de Economia e Feminismo (REF), a Rede Latino-Americana de Mulheres Transformando a Economia (REMTE) e a Marcha Mundial de Mulheres (MMM). Além de promoverem ações, debates e formações políticas focadas nas teses da Economia Feminista, essas organizações também são responsáveis pela maior parte do conteúdo bibliográfico sobre o tema, com destaque para os Cadernos Sempreviva da SOF. Nesse espectro, mencionamos também o SOS Corpo - Instituto Feminista para Democracia que se coloca num campo que coincide com a economia feminista ao identificar uma base material nas relações sociais de sexo.

Dentro do arcabouço teórico que a Economia Feminista enfrenta encontram-se as correntes neoclássicas ou marginalistas, para as quais o processo de valorização do capital é compreendido de acordo com o grau da utilidade do produto e relacionado com a maximização da satisfação dos interesses dos indivíduos. Nisso, tanto os processos de trabalho como as relações sociais embutidas nesses processos são relegadas a segundo plano. Interessa, para esta concepção, o raciocínio matemático e os interesses dos indivíduos supostamente sem gênero, idade e origem. Por meio desse ponto de vista, portanto, é impossível não negligenciar os trabalhos que não seguem as regras gerais da extração de mais-valia, que são separados e hierarquizados socialmente. 
Dentre as críticas mais salientes encontra-se a perspectiva da família e dos papéis desempenhados socialmente por homens e mulheres no interior dela. Para os neoclássicos, as famílias seriam unidades econômicas que atuariam com a racionalidade própria do homo economicus, de modo a maximizar seus ganhos e sua utilidade. Assim, nessa acepção, as famílias escolheriam racionalmente por uma divisão sexual do trabalho, com motivos puramente econômicos. Afinal, é mais vantajoso que as mulheres sejam encarregadas do trabalho doméstico e de cuidados ao invés de ser compartilhado de forma igual com o conjunto da sociedade. Esse olhar sob as famílias e as relações de gênero retira a história como parte da análise, assim como suprime a análise secular das desigualdades de gênero, racionalizando comportamentos que precisam ser compreendidos não de forma individual, senão que inseridos em uma dada sociedade que tem características patriarcais.

A crítica à teoria econômica, entretanto, não se restringe - apenas - à teoria neoclássica ou predominante nas Escolas de Economia. Há alguns pontos de crítica também ao marxismo, especialmente a uma corrente de análise que se vale da centralidade nas relações classistas, de forma desvinculada de outras relações sociais, como as relações de gênero, de raça e de sexualidade.

Do ponto de vista epistemológico e metodológico, a crítica principal é a de que tais teorias ortodoxas ou neoclássicas consideram como atividade econômica apenas a produção de bens e serviços realizados no mercado mediante circulação monetária. Ou seja, consideram em suas análises apenas aquilo que tem valor de troca mercantil. Do mesmo modo, estas teorias predominantes se interessam apenas pelo conjunto de trabalhos considerados produtivos, que geram valor. Com isto, a reprodução social - que envolve os trabalhos que se ocupam da reprodução da vida, como os trabalhos domésticos e de cuidados - são relegados ao conjunto de trabalhos improdutivos ou não mercantis e tendem a ser invisibilizados e negligenciados. Oculta-se, dessa forma, as relações entre produção e reprodução social, desconsiderando que para haver produção capitalista é necessário a reprodução da principal mercadoria do sistema capitalista: a força de trabalho. 
É dentro dessa compreensão que identificamos que o trabalho doméstico realizado de forma gratuita e naturalizada pelas mulheres no interior dos domicílios têm valor econômico e, portanto, deve ser objeto de análise das ciências econômicas. Ter valor econômico, no entanto, não significa ter valor monetário. $\mathrm{O}$ trabalho doméstico tem valor econômico na medida em que ele cria as condições para que outros seres humanos vendam, cotidianamente, a sua força de trabalho. Embora ele contribua como parte necessária da acumulação geral de capital, a sua invisibilização teórica e política, o impede de figurar nas estatísticas da contabilidade nacional, por exemplo, como no cálculo do PIB e entre outras variáveis. Além disso, o trabalho doméstico, ao ser realizado gratuitamente pelas mulheres, gera aumento da mais-valia global do sistema capitalista, na medida em que as mulheres realizam sem qualquer remuneração esse conjunto de tarefas essenciais à reprodução da vida, de forma que nem o Estado nem o mercado precise se preocupar com essa necessidade, além de contribuir - por meio de uma inserção precária nas mulheres na divisão social do trabalho - para rebaixar o salário dos trabalhadores na ativa entendendo o salário como o rendimento suficiente para reprodução da própria força de trabalho.

Nesse sentido, o que a economia feminista propõe, em linhas gerais, é uma análise crítica e uma ampliação do que se entende como econômico e outras categorias analíticas importantes circunscritas a essa ciência, por exemplo, a própria definição de trabalho. Isto é, as economistas feministas não propõem uma simples junção das análises de gênero às teorias predominantes, mas pretendem uma teoria em que as próprias ferramentas analíticas sejam reinventadas.

Assim, o propósito da organização deste dossiê é evidenciar que a Economia Feminista não conforma uma mera vinculação dos estudos sobre as relações entre os gêneros e as teorias, métodos e fórmulas já consolidadas na ciência econômica, e sim se constitui em um campo de estudos forjado por grupos feministas no interior dessa ciência. Em síntese, as teóricas da Economia Feminista elaboram teorias, métodos e fórmulas que alcançam a reprodução social e não apenas a produção de bens e serviços. 
Este dossiê, portanto, ganha demasiada importância em um contexto acadêmico e político de irrompimento de novas questões e de novos problemas de pesquisa. A Economia Feminista, desse ponto de vista, se apresenta como uma importante ferramenta com potencial de contribuir nos principais debates, tanto no âmbito do movimento social de mulheres como no debate acadêmico. Além disso, o conjunto de textos aqui apresentados adquire relevância marcante na medida em que o debate sobre a Economia Feminista já é uma realidade em afirmação em vários países e já tem sido utilizada por movimentos de mulheres, no entanto, sem figurar como um debate pungente nas Universidades brasileiras.

É nesse sentido que inauguramos este dossiê temático com a transcrição de uma fala de Marielle Franco, no seminário "Diálogos difíceis, diálogos possiveis: questões contemporâneas dos feminismos", realizado na cidade do Rio de Janeiro entre 28 e 30 de março de 2017. Marielle Franco foi uma socióloga brasileira, vereadora da cidade do Rio de Janeiro e brutalmente assassinada no dia 14 de março de 2018, por crime político. A fala de Marielle Franco vai ao encontro do tema deste dossiê na medida em que expõe a sua perspectiva de um feminismo que seja pautado na vida cotidiana e pela defesa de políticas públicas que considerem as condições materiais de existência das mulheres negras e pobres brasileiras. Publicamos esse texto em homenagem à sua trajetória de luta em defesa dos direitos humanos, com respeito e solidariedade à sua família.

Publicamos, também, duas relevantes traduções. A primeira delas é um texto de Antonella Picchio, traduzido para a língua portuguesa por Maria Fernanda Cardoso de Melo, Daniela Salomão Gorayeb, Juliana de Paula Filleti, Olivia Bullio Mattos e Georgia Christ Sarris, publicado neste dossiê com o título "Trabalho feminino no cerne do mercado de trabalho". O artigo corresponde ao quinto capítulo do livro "Social Reproduction: The Political Economy of the Labour Market", de Picchio, publicado em 1992 pela Cambridge University Press. Passados 26 anos desde a publicação, o texto reproduzido neste dossiê é de extrema relevância na medida em que a análise de Picchio permanece atual e uma referência importante para a Economia Feminista e para os estudos sobre trabalhos domésticos e de cuidados, porque nele a autora especifica a relação 
entre produção e reprodução. A partir de uma análise estatística sobre a distribuição do trabalho doméstico entre mulheres e homens na Itália e na França do final da década de 1980; de confrontar de forma veemente os pressupostos neoclássicos, especialmente a visão da família presente nas obras de Gary Becker; de questionar o potencial político das mulheres trabalhadoras apenas relacionado ao assalariamento, neutralizando o trabalho doméstico; e de abordar o Estado como a instituição que regula o arranjo entre o processo de acumulação e o processo de reprodução social, a autora argumenta que o trabalho doméstico seria o elo na relação entre a produção e a reprodução que sustenta o processo de acumulação de capital.

Embora a apreciação estatística de Picchio possa estar defasada para o momento atual, há argumentos relevantes, por exemplo, de que para o casamento aumentaria o tempo de trabalho doméstico das mulheres - e aumentaria de acordo com o aumento da família -, em relação às mulheres solteiras; e diminuiria o tempo de trabalho doméstico dos homens, em relação aos homens solteiros. Além da dupla jornada ser compreendida como um fenômeno feminino. No entanto, a relevância maior do texto de Picchio está em sua análise sobre a dimensão capitalista do trabalho doméstico ao questionar as dimensões de valor-trabalho e uso do tempo, compreender o papel do Estado na relação entre produção e reprodução e indicar as mulheres como sujeito político capaz de organizar lutas, em amplitude internacional, por melhores condições de vida e de trabalho.

A outra tradução publicada no presente dossiê é um texto recente escrito por Cristina Carrasco, traduzido para a língua portuguesa por Luiza Mançano Gomes e Maria Júlia A. G. Montero. O texto de Carrasco "A economia feminista: um panorama sobre o conceito de reproducão", publicado originalmente na Revista Ekonomiaz, em 2017, apresenta e atualiza os debates mais atuais elaborados pelas economistas feministas. Partindo do ponto de vista da reprodução social, Carrasco recupera a forma como alguns pensadores predominantes na Ciência Econômica elaboraram os esquemas reprodutivos, passando por diversas formulações que encaminham a ideia central de seu trabalho de que há uma insustentabilidade no sistema socioeconômico atual, diante da qual seria 
necessário estabelecer uma ruptura com a atual visão de mercado para uma perspectiva que coloque no centro a vida humana.

Além das duas importantes traduções, o dossiê conta com outros sete artigos. Percorrendo o debate teórico da Economia Feminista, Marilane Oliveira Teixeira, no artigo "A economia feminista e a crítica ao paradigma econômico predominante", discute a construção de um novo marco conceitual para a disciplina da economia tendo como referência a insatisfação crescente das economistas, pesquisadoras e feministas com a abordagem da economia dominante. A autora aborda as várias vertentes com foco na sustentabilidade da vida humana, por se constituir em um instrumento valioso de análise que permite uma crítica global ao sistema capitalista e à economia de mercado e, por isso, foi mais rapidamente incorporada pelos movimentos feministas que questionam o liberalismo econômico e a globalização.

Já Fabiana Sanches Grecco, no artigo "O viés androcêntrico da Ciência Econômica e as críticas feministas ao homo economicus", aborda a noção de homo economicus na Ciência Econômica por meio da denúncia das economistas feministas de que essa ciência seria centrada em um viés androcêntrico. Ao percorrer a concepção de indivíduo (egoísta, maximizador de lucro, interessado exclusivamente no mercado, calculista e racional) em diferentes abordagens da economia, a autora apresenta as críticas feministas que indicam profundas reformulações na produção do conhecimento, por meio de um viés feminista que considerem valores extra-mercadológicos como as emoções, a solidariedade, a reciprocidade.

A dimensão política da Economia Feminista, no Brasil, é evidenciada por Isabelle Hillenkamp e Miriam Nobre em "Agroecologia e feminismo no $V$ ale do Ribeira: contribuição para o debate sobre reproducão social'. Nesse artigo, as autoras apresentam os resultados de uma pesquisa-ação realizada junto a uma rede de mulheres agricultoras do município de Barra do Turvo, no Vale do Ribeira (SP), apoiada pela ONG feminista SOF, no âmbito de um projeto de promoção da agroecologia. As autoras contextualizam as relações sociais avistadas no Vale do Ribeira: a política de Assistência Técnica e Extensão Rural (ATER) e a agroecologia feminista. A partir dessa pesquisa, as autoras destacam que a agroecologia se define por um projeto 
político amplo e que uma abordagem feminista que afirme os propósitos de autonomia e sustentabilidade exigiria uma dupla transformação - das relações com a natureza e das relações de gênero.

No mesmo âmbito, o artigo de Renata Faleiros Camargo Moreno, "Economia Feminista em movimento: experiências e desafios teóricopoliticos a partir das lutas das mulheres", apresenta e teoriza sobre a economia feminista a partir da perspectiva da luta política das mulheres organizadas. Renata Moreno apresenta a trajetória de organização das mulheres na Marcha Mundial de Mulheres (MMM) e - ao apresentar suas metodologias de formação, seus valores solidários e suas lutas cotidianas de conquista/ ampliação de direitos coletivos - demonstra que a economia feminista, além de uma análise teórica, é uma ferramenta de ação. Ao realizar esse levantamento a autora demonstra que, no Brasil, o tema da Economia Feminista rompe os muros das Universidades a partir do momento em que ele se apresenta como um instrumento real de organização e atuação política do movimento de mulheres.

Olhando para configurações do mercado de trabalho brasileiro, Eugenia Troncoso Leone e Luciana Portilho, no artigo "Inserção de mulberes e homens com nivel superior de escolaridade no mercado de trabalbo brasileiro" apresentam um panorama da desigualdade de rendimentos entre homens e mulheres em profissões de nível superior no ano de 2013. A problemática desvendada pelas autoras revela que, embora as ocupações que exigem ensino superior, no Brasil, são as que auferem os maiores rendimentos, mesmo as mulheres sendo em torno de 50\% dos ocupados, ainda sim o salário médio delas é demasiadamente inferior aos dos homens. Aqui expressa-se mais uma contradição da divisão sexual do trabalho: quanto mais qualificadas são as mulheres, mais aumenta o fosso salarial delas em relação aos homens, o que pode ser explicado pela segregação ocupacional no mercado de trabalho, na qual mulheres - embora sejam a maioria no ensino superior - migram para aquelas ocupações tipicamente "femininas", tais como o trabalho de cuidados e a educação. Não à toa, essas são as atividades produtivas de menor salário médio na sociedade brasileira, o que reforça - no agregado - a desigualdade salarial. 
Ampliando o debate sobre o Brasil para uma dimensão global, Thaís de Souza Lapa, no artigo "Divisão sexual do trabalho sob a ordem neoliberal', apresenta uma reflexão sobre a divisão sexual do trabalho sob a ordem neoliberal e seus efeitos na indústria. A partir da análise do uso estratégico de força de trabalho feminina em cadeias globais de produção, a autora reafirma a tese de que o gênero é um elemento chave na globalização em sua nova fase de acumulação neoliberal. Lapa chama atenção para a análise das condições de trabalho de mulheres em países periféricos, rumo aos quais empresas externalizam sua produção e em que o uso do trabalho feminino se dá em manufaturas nas pontas das cadeias globais, por meio de terceirizações.

Já Catarina Casimiro Trindade, no artigo "Além do económico: reflexões sobre os significados do xitiki, uma prática informal de poupança de Maputo, Moçambique", apresenta as "Associações de Poupança e Crédito Rotativo" (ROSCAs) - práticas financeiras informais, fora de instituições bancárias - e o xitiki, que é um tipo dessas práticas, difundida especialmente entre as mulheres, em Moçambique. A autora apresenta as dimensões não capitalistas dessas práticas, trazendo elementos sobre os significados atribuído ao xitiki, que incluem, entre outras, redes de parentesco, vizinhança, a comunidade religiosa, associações locais e grupos informais de poupança.

Além das duas traduções e dos seis artigos acima apresentados, o dossiê conta, também, com duas resenhas de livros importantes que dialogam com o tema aqui proposto. Bianca Briguglio analisou o livro "Gênero e Desigualdades: Desafios da Democracia no Brasil', de Flávia Biroli, publicado em 2018 pela Editora Boitempo, em que são abordados os temas participação política, divisão sexual do trabalho, os trabalhos de cuidado e responsabilidades, família e da maternidade, aborto, sexualidade e autonomia. Já Priscila von Dietrich e Cecília Severo analisaram o livro "Calibã e a bruxa: mulheres, corpo e acumulação primitiva", de Silvia Federici, publicado pela Editora Elefante, em 2017, em que Federici aborda a perseguição aos hereges, a questão da acumulação primitiva e a relação com o trabalho e a degradação da vida das mulheres e a questão da 
domesticação do corpo rebelde e a colonização como mecanismos que se reinventam a cada crise e expansão do capital.

Para concluir, aproveitamos para agradecer a todas as autoras, tradutoras, editoras, revisoras e pareceristas que contribuíram para a construção deste dossiê e ressaltamos a importância desta publicação na construção acadêmica desse campo de estudos feministas no Brasil, contando com publicações de textos de importantes pesquisadoras da área. Cabe destacar também, os limites desse dossiê em problematizar de modo insuficiente as dimensões étnicas e raciais, especialmente considerando as especificidades das imbricações das relações sociais de poder no país.

\section{REFERÊNCIAS BIBLIOGRÁFICAS}

BERGMANN, Barbara. "The Economics of Women's Liberation". In: "Successful Women in the Sciences". Annals of the New York Academy of Sciences, 208 (March): 154-60, 1973.

CARRASCO, Cristina. "La Economía Feminista: Una apuesta por otra economía". In: VARA, María Jesús (ed.). "Estudios sobre género y economía". Madrid: Akal, 2006.

ENGLAND, Paula. "The separative self: androcentric bias in neoclassical assumptions". In: FERBER, Marianne A.; NELSON, Julie A. (eds.). "Beyond Economic Man: Feminist Theory and Economics". Chicago: University of Chicago Press, 1993.

FERBER, Marianne A.; NELSON, Julie A. (eds.). "Beyond Economic Man: Feminist Theory and Economics". Chicago: University of Chicago Press, 1993.

HARDING, Sandra. "Conclusion: Epistemological Questions". In: HARDING, Sandra (ed.). "Feminism \& Methodology: Social Science Issues". Indiana University Press/Open University Press, pp. 181-190, 1987. 
HARDING, Sandra. "Rethinking Standpoint Epistemology: What is 'Strong Objectivity"'. In: Linda Alcoff e Elizabeth Potter (eds). "Feminist Epistemologies". New York: Routledge, 1992.

HARDING, Sandra. "Can feminist thought make economics more objective?”. Feminist Economics, 1:1, 7-32, 1995.

PÉREZ OROZCO, Amaia. "Economía del género y economia feminista ¿Conciliación o ruptura?”. Revista Venezolana de Estúdios de la Mujer. Caracas, Vol. 10 - N²4, 2005.

PICCHIO, Antonella. "A Economia Política e a Pesquisa Sobre as Condições de Vida”. In: FARIA, Nalu; MORENO, Renata. “Análises feministas: outro olhar sobre a economia e a ecologia”. São Paulo: SOF, Coleção Cadernos Sempreviva. Série Economia e Feminismo, 2012. PUJOL, Michèle. "Feminism and anti-feminism in early economic thought". London: Edward Elgar, 1992. 